* Mestrando em Direito pela Universidade Nove de Julho UNINOVE. Especialista em Direito Constitucional e Administrativo pela Escola Paulista de Direito - EPD. Especialista em Direito Tributário pelo Centro Universitário das Faculdades Metropolitanas Unidas - FMU. Pesquisador bolsista da CAPES. E-mail: jeferson@joliveiraadv.com.br

** Doutor em Direito pela Pontifícia Universidade Católica de São Paulo. Mestre em Direito pela Pontifícia Universidade Católica de São Paulo. professor permanente do Mestrado em Direito e da Graduação da Universidade Nove de JulhoUNINOVE. Professor Convidado da Pós-Graduação lato sensu da PUC/COGEAE e da Escola Paulista da Magistratura. Prof. Titular de Direito Civil da Faculdade de Direito de São Bernardo do Campo. E-mail: benamarcelo@gmail.com

\section{Responsabilidade Corporativa como Ferramenta De Desenvolvimento Socioeconômico}

\section{Corporate Responsibility as a Tool for Socio- ECONOMIC DEVELOPMENT}

\section{Jeferson Sousa Oliveira* Marcelo Benacchio**}

Como citar: OLIVEIRA, Jeferson Sousa; BENACCHIO, Marcelo. Responsabilidade corporativa como ferramenta de desenvolvimento socioeconômico. Revista do Direito Público, Londrina, v. 13, n. 3, p. 175-188, dez. 2018. DOI: 10.5433/24157108104-1.2018v13n3 p 175. ISSN: 1980-511X.

Resumo: Com o desenvolvimento do capitalismo e o advento da globalização, o mundo experimentou uma evolução comercial nunca antes vislumbrada, a qual não foi capaz de levar o pleno desenvolvimento à humanidade, marcando-a com novas mazelas comumente ignoradas por aqueles que detêm o poder econômico. Objetiva-se assim, analisar a amplitude e necessidade da responsabilização das companhias em decorrência do exercício de sua atividade. Vale-se do método hipotético-dedutivo. Conclui-se que a responsabilidade corporativa é uma ferramenta de gestão essencial para a redução dos problemas sociais modernos, propiciando um mercado mais humanizado.

Palavras-Chave: Direito econômico; Responsabilidade social; Direitos humanos; Desenvolvimento.

Abstract: With the development of capitalism and the advent of globalization, the world experienced a commercial evolution never before seen. Unfortunately, this advancement did not thoroughly help humanity as many ills were and are being ignored by those who hold economic power. In light of this, the objective of this paper is to analyze the extent and necessity of a companies' responsibility as a result of their corporate activities. This study uses the hypotheticaldeductive method. Finally, this research concludes that corporate responsibility is an essential management tool for reducing modern social problems as it provides for a more humanized market.

Key-words: Law and economics; Social responsibility; Human rights; Development. 


\section{INTRODUÇÃO}

Com o desenvolvimento da atividade econômica ao longo dos séculos, a humanidade gradativamente caminhou rumo à integração do mercado, refletindo modernamente na globalização.

Até o advento da globalização, o capitalismo passou por diversas mudanças conforme os anseios sociais da época, o que resultou em diferentes formas de proteção da coletividade ao abuso do poder econômico.

Partindo do não intervencionismo estatal no mercado, cada vez mais sua intervenção foi requerida a fim de impedir que violações aos direitos individuais e coletivos ocorressem, não tendo sido possível, em contraposição, limitar a perpetração de severas discrepâncias econômicas na sociedade.

Com o passar do tempo, o Estado se mostrou incapaz de preservar de forma plena a dignidade humana, comumente sacrificada em nome do desenvolvimento puramente econômico.

Assim, o neoliberalismo surge como uma proposta que permite o Estado guiar as relações de mercado rumo à consecução dos interesses nacionais, propiciando o desenvolvimento social.

Ocorre que a maneira como a atividade comercial passou a ser desempenhada no mundo globalizado impede que a sociedade se desenvolva da maneira ideal, exigindo o sacrífico de muitos para assegurar o bem-estar de poucos.

Isso fez com o que acúmulo de riqueza tomasse o protagonismo do mercado, deixando de ser um instrumento para o desenvolvimento e se tornando um fim em si mesmo, colocando os valores humanos em segundo plano.

Com esse câmbio de valores, a função social das empresas passou a se limitar apenas ao seu objetivo precípuo, gerar lucro, atendendo apenas aos interesses de seus investidores, deixando de lado qualquer outro.

No entanto, com o desenvolvimento social estando cada vez mais distante, passou-se a buscar maior amplitude na responsabilização das companhias pelos efeitos negativos de seus atos de mercado e pela centralização de toda a riqueza gerada.

Deste modo, servir ao desenvolvimento social se tornou mais que um anseio social, mas uma obrigação moral que deve ensejar a adoção de um modelo de gestão empresarial preocupado em garantir a correta observância dos Direitos Humanos, sem permitir que o capital gere segregação entre as pessoas.

Destarte, a partir de uma visão macroeconômica, busca-se analisar os efeitos negativos do mercado sobre o desenvolvimento social e eventual necessidade de mudança na maneira como as corporações têm se responsabilizado por suas atividades negociais. Para tanto, vale-se do método hipotético-dedutivo, bem como de revisão bibliográfica a fim de versar sobre a temática ora proposta.

\section{GLOBALIZAÇÃO E SEUS REFLEXOS SOCIAIS}


Com a evolução da sociedade muitos valores comuns passaram por mudanças, tornando as relações interpessoais ainda mais frequentes, principalmente quando dotadas de caráter comercial.

Indiscutivelmente, a globalização como se conhece atualmente, é fruto da exploração da atividade econômica, a qual passou por significativas mudanças nos últimos séculos, em especial, por conta do modelo econômico adotado em grande parte do planeta.

O capitalismo, hoje, o modelo econômico mais adotado no mundo, teve sua raiz teórica idealizada por Adam Smith, em 1776, com a publicação da obra A Riqueza das Nações.

O referido teórico defendia que o mercado seria capaz de se autorregular, sendo necessária a intervenção estatal apenas para mantê-lo em pleno funcionamento, o que proporcionaria melhores condições financeiras à sociedade e consequentemente seu desenvolvimento.

Se valendo dessa premissa, muitas empresas despontaram no cenário econômico ocidental, explorando tudo o que o capitalismo tinha a lhes oferecer.

Com isso, não demorou até que os efeitos da atividade comercial predatoriamente explorada começassem a afetar a sociedade, gerando discrepâncias econômicas consideráveis entre os donos dos meios de produção e aqueles que vendiam sua força de trabalho.

O modelo clássico de mercado ignorava e recusava a ideia de poder econômico. $\mathrm{Na}$ práxis, todavia, os defensores do poder econômico, porque plenamente conscientes de sua capacidade de dominação, atuando a largas braçadas sob a égide de um princípio sem princípios - o princípio do livre mercado -, passaram e desde então permanecem a controlar os mercados (GRAU, 2015, p. 22).

Ante o clamor social por melhorias na qualidade de vida, as quais não vieram com o capitalismo puro, surge o socialismo, e mais tarde, como resposta, emerge o Estado do Bem-Estar Social.

Neste, embora o modelo liberal ainda fosse o sistema econômico largamente adotado no ocidente, o Estado tomou para si o dever de amparar a sociedade frente aos abusos do mercado, o que acabou por onerar seus cofres.

"O estado de bem-estar tinha de arcar com os custos marginais da corrida do capital pelo lucro e tornar a mão-de-obra deixada para trás novamente empregável - um esforço que o próprio capital não empreenderia ou não poderia empreender." (BAUMAN, 1998, p. 51).

Tal modelo de gestão pública se mostrou custoso e ineficiente em muitos países, ensejando mudanças consideráveis na maior parte deles. Para tanto, John Maynard Keynes surge como teórico do neoliberalismo, propondo a instituição de um dirigismo estatal sobre o mercado a fim de que o mesmo passasse a contribuir para o efetivo desenvolvimento social e para a redução das já consolidadas discrepâncias econômicas.

Mesmo com as mudanças na maneira como a sociedade foi tratada pelo mercado ao longo dos anos, este se mostrou plenamente ativo, ensejando uma célere intensificação de suas relações e pouca preocupação com o bem-estar coletivo.

Assim, desde o surgimento do liberalismo, "a economia tem impulsionado a globalização, 
especialmente por meio do barateamento das comunicações e dos transportes." (STIGLITZ, 2007, p. 63).

Não demorou muito até que o mundo se globalizasse, tornando internacional grande parte das relações negociais, e novamente prometendo que o desenvolvimento financeiro atingiria a todos.

Deste modo, com o surgimento da globalização e a popularização da internet, o fluxo de capital, pessoas e bens atingiu um novo patamar, um nunca antes vislumbrado na história humana.

Isso agravou ainda mais a condição social de milhões de pessoas ao redor do planeta, em especial devido ao modelo de atuação empresarial transnacionalizado, pautado na mobilidade (BAUMAN, 1999), deixando ao Estado anfitrião apenas as consequências da atividade explorada, sem compartilhar suas benesses.

Entretanto, buscando o desenvolvimento econômico, assim como as companhias privadas, muitos países instituíram empresas públicas para explorar setores essenciais sob o regime de monopólio ou tão somente para concorrer com a iniciativa privada. Assim, pode-se observar que “o Estado moderno nasce sob a vocação de atuar no campo econômico.” (GRAU, 2015, p. 19).

Em tal condição, é possível compreender que "a cooperação entre Estado e mercado no capitalismo é a regra; o conflito entre eles, quando acontece, é a exceção.” (BAUMAN, 2010, p. $31)$.

Logo, em face do capitalismo, o bem-estar social foi deixado de lado, tornando-se mera consequência do acumulo de riqueza, enquanto, na verdade, o acumulo de riqueza deveria ser utilizado para propiciar o bem-estar de todos.

\begin{abstract}
Algunos han saludado la globalizatión como el bálsamo de todos los males, mientras que otros la han estigmatizado como el principio del fin. Aunque, como casi todo en la vida, la globalizatión presenta claroscuros, lo que está claro es que es un fenómeno inevitable. La liberalización de los mercados y el desarrollo de las tecnologías de la información han propiciado el avance imparable de la globalización (SANTONJA, 2009, p. 39).
\end{abstract}

Tem-se assim que custo por deixar o capitalismo agir conforme seus interesses é a autodestruição do mercado e o sacrifício da dignidade humana em nome do acúmulo de uma riqueza que só existe para uma pequena minoria.

Com isso, ante a ilusória ideia de desenvolvimento pregada pelo capitalismo, os agentes exploradores da atividade econômica restringiram sua função social a gerar lucro, eximindo-se de qualquer outra responsabilidade pelos efeitos negativos do negócio.

Essa ausência de comprometimento empresarial acabou por afetar as relações laborais, o equilíbrio do meio ambiente, o próprio regime concorrencial e o bem-estar coletivo como um todo.

Segundo Carlos Ayres Britto (2016, p. 45), “[...] o presente modelo de globalização reduz 
tão sistematicamente postos de trabalho para o homem de baixa instrução escolar que já se pode dizer que a luta de classe, hoje, é entre desempregados e desempregadores."

E mais: a globalização ameaça a sociedade civil, na medida em que: (i) está associada a novos tipos de exclusão social, gerando um subproletariado (underclass), em parte constituído por marginalizados em função da raça, nacionalidade, religião ou outro sinal distintivo; (ii) instala uma contínua e crescente competição entre os indivíduos; (iii) conduz à destruição do serviço público (= destruição do espaço público e declínio dos valores do serviço por ele veiculados). Enfim, a globalização, na fusão de competição global e de desintegração social, compromete a liberdade (GRAU, 2015, p. 49).

Nessas condições, conceber um conceito mais amplo de função social da empresa mostra-se uma necessidade imediata, pois ao mesmo tempo em que a globalização implicou no crescimento das relações comerciais, resultou no enfraquecimento da defesa de direitos individuais, coletivos e sociais por todo o mundo moderno.

Não basta ainda que haja ideais teóricos sem uma efetiva responsabilização social das companhias pelo uso de recursos humanos e naturais, devendo os frutos da atividade comercial beneficiar reflexamente à sociedade, ou então diferentes povos tenderão a se insurgir contra o sistema capitalista e a globalização.

Não admira então que o primeiro grande protesto moderno contra a globalização, ocorrido em Seattle, em dezembro de 1999, no que deveria ser o começo de uma nova rodada de negociações sobre o comércio que levaria a uma maior liberalização, tenha sido uma surpresa para os defensores dos mercados abertos. A globalização havia conseguido unir gente de todo o mundo - contra a globalização. Os operários fabris dos Estados Unidos viam seus empregos ameaçados pela concorrência da China. Os agricultores de países em desenvolvimento viam seus empregos ameaçados pelos altos subsídios agrícolas americanos. Os trabalhadores da Europa viam a proteção do emprego, conquistada a duras penas, sendo atacada em nome da globalização. Os militantes contra a aids viam os novos acordos comerciais aumentando o preço dos remédios a níveis fora do alcance para boa parte do mundo. Os ambientalistas sentiam que a globalização punha em perigo sua luta de uma década para estabelecer regulamentações a fim de preservar nossa herança natural. Aqueles que queriam proteger e desenvolver suas heranças culturais também percebiam a intrusão da globalização. (STIGLITZ, 2007, p. 66-67).

Como aduzido, com o acesso à internet, diversos grupos sociais passaram a ter maior facilidade para se organizar em prol de um ideal comum, o que torna ainda mais efetivo qualquer requerimento social aos suprimento de seus anseios.

"Al igual que han contribuido a la globalización del comercio y de las empresas, las nuevas tecnologías han multiplicado las possibilidades de interrelación entre los miembros más activos de la sociedad civil. La sociedad civil se ha organizado y se ha globalziado." (SANTONJA, 2009, 
p. 39).

Destarte, fazer cumprir a função social da empresa nada mais é do que um dever moral que vem ganhando respaldo legal em diversos Estados, de modo a contribuir para a promoção e manutenção da dignidade humana, bem como para que se possa ter maior proveito de tudo o que o capitalismo pode oferecer ao mundo globalizado.

\section{ATIVIDADE ECONÔMICA E FUNÇÃO SOCIAL DA EMPRESA}

Como versado, o capitalismo pregou um desenvolvimento social nunca alcançado, pelo contrário, tem se mostrado cada vez mais distante, ante o aumento das discrepâncias econômicas entre ricos e pobres.

E é sob esse enfoque que se entende que o desenvolvimento deve estar pautado na égide da função social da empresa, vez que em virtude de seu elevado poder econômico, as companhias acabam por adquirir maior responsabilidade com relação ao meio no qual estão insertas, devendo assim agir de maneira a promover o bem-estar coletivo.

Ademais, auxiliar no desenvolvimento social ganha uma face moral à medida que muitas companhias abusam do seu poder econômico para conquistar vantagens que de outra forma não teriam acesso.

Com isso, os interesses financeiros das companhias sobrepõem-se aos sociais, sendo defendidos ou simplesmente tolerados pelo Estado.

"O fato é que a apologia ideológica do mercado é produzida em função exclusivamente do interesse do investidor, que é o de baixar os custos que oneram a empresa (os salários, os tributos e as cargas sociais).” (GRAU, 2015, p. 47).

Embora beneficiar aqueles que não são investidores seja considerado um dispêndio econômico, deve-se compreender que o lucro é gerado a partir da sociedade, razão está que reafirma a necessidade da adoção de uma atuação econômica mais humanizada, até mesmo porque o capitalismo possui o desenvolvimento social como seu fim primordial.

Sabendo que das cem maiores economias do mundo, vinte nove são empresas privadas (SANTONJA, 2009), questiona-se a quem estas estão a servir, se não a uma pequena minoria.

Assim, reduzir o desenvolvimento a um seleto grupo nada mais é do que contrapor-se aos ideais humanistas, tornando o acúmulo de capital um fim, enquanto deveria ser apenas um meio.

Diferentemente do que se possa imaginar, o Estado não é capaz de sozinho garantir a manutenção da dignidade humana - como se pôde notar com a evolução do capitalismo - mas tão somente de estabelecer os limites e as condições nas quais a economia deve se desenvolver sem causar danos irreversíveis à sociedade.

Nessa linha, evidenciando a incapacidade estatal de promover o pleno desenvolvimento social, Joseph Eugene Stiglitz (2007, p. 84) aponta que "um país talvez queira elevar o salário mínimo, mas descobre que não pode porque as empresas estrangeiras que nele operam decidirão 
mudar-se para um país com salários mais baixos."

Tal situação é reflexo da grandeza do poder econômico das transnacionais e da maneira como elas são capazes de influenciar na tomada de decisões de um governo, tornado o Estado refém de seus interesses.

Nessa condição, embora a função social teoricamente possua uma natureza humanista, inegavelmente é possível afirmar "numa frase, o humanismo dos dias atuais ainda é mais de fachada do que autêntico." (BRITTO, 2016, p. 45).

Assim, manter o exercício da atividade econômica sem efetivar uma real gestão empresarial pautada na função social e na promoção do bem-estar coletivo, visando reduzir as desigualdades sociais e preservar a dignidade humana, é o mesmo que conviver em tempos modernos com o liberalismo econômico travestido de neoliberalismo, vez que os Estados acabaram por se curvar aos interesses do mercado.

Além disso, o capitalismo falha escandalosamente em sua capacidade de gerar empregos, de oferecer segurança aos que consegue empregar e de alentar os empregados com as perspectivas de melhores salários. Aumentam significativamente as desigualdades, tanto nas sociedades desenvolvidas quanto nas regiões periféricas (GRAU, 2015, p. 51).

Diante desse cenário torna-se difícil acreditar que as empresas já estejam cumprindo com sua função social, haja vista ainda estarem contribuindo para o aumento da desigualdade financeira no mundo e não demonstrarem qualquer contramedida capaz de assegurar uma vida digna àqueles que a eles estão de alguma maneira relacionados.

Como aduzido, os efeitos negativos da falta de humanização do mercado não afetam apenas o países não desenvolvidos, mas também aqueles entendidos como potências econômicas, o que pode ser notado quando se considera que "mais de 5 milhões de britânicos se encontram em estado de pobreza absoluta." (GRAU, 2015, p. 53).

Nos países mais ricos é demasiado comum haver pessoas imensamente desfavorecidas, carentes das oportunidades básicas de acesso a serviços de saúde, educação funcional, emprego remunerado ou segurança econômica e social. Mesmo em países muito ricos, às vezes a longevidade de grupos substanciais não é mais elevada do que em muitas economias mais pobres do chamado Terceiro Mundo (SEN, 2010, p. 29).

Assim, a existência e o cumprimento da função social da empresa passam a ser mais um anseio coletivo ante a maneira predatória como o mercado tem se portado, principalmente a partir do advento da globalização, sem que o desenvolvimento alcançasse a todos.

Quem mais tem sentido os efeitos do mercado são os Estados não desenvolvidos, ante o grande número de pessoas que vivem em condições aquém do considerado digno à espécie 
humana.

“Em anos recentes, a América Latina e a Rússia também ficaram desapontadas com a globalização. Elas abriram seus mercados, mas a globalização não cumpriu suas promessas, especialmente para os pobres.” (STIGLITZ, 2007, p. 71-72).

Logo, uma atuação empresarial descomprometida com a função social não condiz com a própria ideia de desenvolvimento humano, prendendo a companhia em ideais individualizados, sob uma perspectiva microeconômica, causando grandes danos ao meio no qual se faz presente.

Importante destacar ainda que cumprir a função social não é apenas eximir-se de prejudicar a condição humana, mas também adotar um posicionamento ativo, visando agregar um valor coletivo à atividade desempenhada (GRAU, 2015).

É pertinente ainda destacar que a pobreza gerada pela centralização do capital afeta a toda a sociedade perante seus próprios pares, criando discriminação e segregação entre aqueles que podem ou não consumir, lançando indivíduos à margem do amparo estatal e rumo à marginalização.

Cada vez mais, ser pobre é encarado como um crime; empobrecer, como o produto de predisposições ou intenções criminosas - abuso de álcool, jogos de azar, drogas, vadiagem e vagabundagem. Os pobres, longe de fazer jus a cuidado e assistência, merecem ódio e condenação - como a própria encarnação do pecado (BAUMAN, 1998, p. 59).

Percebe-se que no mundo globalizado, desenvolvido ao redor do mercado, a pobreza ainda é uma ameaça constante na vida de inúmeras famílias, assombrando-as ante a rejeição social e à exclusão do mercado consumista.

Longe de ser uma exceção, a pobreza é uma realidade mundial, atingindo milhões de pessoas ao redor do planeta. Com isso, a ausência de desenvolvimento econômico é capaz de ceifar qualquer perspectiva de dias melhores, tomando a dignidade de muitos pelo bem de pouco abastados financeiramente.

Não é demais pensar na gravidade da concentração de renda quando se tem que mais de dois terços da população mundial vive abaixo da linha da pobreza, recebendo menos de dois dólares por dia (SANTONJA, 2009).

"A essa altura, já ficou claro que a abertura dos mercados (redução das barreiras ao comércio, abertura aos fluxos de capital) por si só não 'resolverá' os problemas da pobreza, e pode até piora-los. O que é preciso é mais ajuda e um regime de comércio mais justo.” (STIGLITZ, 2007, p. 76).

Assim, é possivel notar que o mero incentivo para que mais pessoas integrem o mercado não será o suficiente para melhorar a fragilizada condição humana, sendo necessário pensar mais além e efetivar ações capazes de propiciar uma real existência digna a todos os povos, não se 
limitando apenas a divagações teóricas.

\section{RESPONSABILIDADE CORPORATIVA E DESENVOLVIMENTO ECONÔMICO}

Como apontado, a maneira como o capitalismo tem sido utilizado nos últimos séculos acabou por colocar o desenvolvimento social em segundo plano, ofuscado pelo desenvolvimento econômico de poucos.

Tal situação é reflexo do egoísmo típico das relações comerciais e seu caráter predatório, onde o mais forte busca se manter em destaque ditando as regras do mercado. Isso afetou a diferentes povos, ao passo que "[...] a pobreza no mundo em desenvolvimento aumentou nas duas últimas décadas.” (STIGLITZ, 2007, p. 71).

Essa condição deve-se ao fato de que os agentes que exploram a atividade econômica, embora acreditem cumprir com sua função social, estão longe de agir com a amplitude necessária para sanar os problemas sociais trazidos pela globalização e pela intensificação das relações negociais.

Como destacado, as companhias não tendem a se preocupar com os reflexos de suas atividades, considerando apenas aspectos atinentes ao seu próprio bem-estar e na consecução de seus objetivos precípuos.

Nessa linha, Eros Roberto Grau (2015, p. 48) afirma que "o capitalismo é essencialmente conformado pela microrracionalidade da empresa, não pela macrorracionalidade reclamada pela sociedade."

E é com base nesse aspecto que se entende que a função social não está sendo efetivamente cumprida, devendo assim haver maior responsabilização corporativa quanto aos efeitos negativos de sua atividade comercial, bem como, a adoção de um modelo de gestão empresarial que opte por um posicionamento ativo, auxiliando o Estado na promoção de um real desenvolvimento socioeconômico.

El modelo capitalista y la Responsabilidad Social de la Empresa (RSE), también llamada Responsabilidad Corporativa (RC), está en el centro del debate económico, social y político en todo el mundo desarrollado. Existen grandes controversias sobre su alcance en el ámbito de lá empresa y se plantea la pergunta de si estamos ante una auténtica, potente y novedosa herramienta de gestión empresarial que comporta una nueva economía de la empresa y, como consecuencia de ello, se abre paso una reformulación del modelo capitalista liberal (SANTONJA, 2009, p. 27).

Acredita-se, com isso, que as empresas devem contribuir com o desenvolvimento dos diferentes povos, vez que constantemente estão a explorar recursos naturais e humanos em prol de sua atividade.

Ou seja, auxiliar o Estado na promoção do desenvolvimento humano é uma dever 
moral, constituindo-se em uma contrapartida pelos danos causados a fim de descentralizar o real desenvolvimento trazido pelo mercado.

Tal contrapartida pode assumir diferentes aspectos, dentre eles, o ambiental. Assim, evitar agir de maneira a não degradar o meio ambiente de forma predatória se mostra de suma importância, pois o mesmo é dotado de essencialidade para a manutenção a vida no planeta.

Logo, desequilibrar o ecossistema, colocando em risco toda a vida existente em nome do acúmulo de capital não demonstra ser algo razoável, até mesmo porque o capital deve ser usado para promover uma existência digna a todos.

Por outro lado, como destacado, a exclusão social gerada em nome do capital demonstra a natureza humana, dotada de ganância e sedenta por poder, segregando seus próprios pares.

A pior parte da exclusão gerada pelo capitalismo é o fato de que muitos se negam a tentar compreender o problema e buscar meios de sana-lo, limitando-se apenas a ignora-lo sob a esperança de não serem atingidos por seus efeitos.

Assim, afirma Stiglitz (2007, p. 72-73) que "os pobres têm poucas oportunidades para se manifestar. Quando falam, ninguém escuta; quando alguém escuta, a resposta é que nada pode ser feito; quando lhes dizem que algo pode ser feito, isso nunca acontece."

Tal condição está longe de ser a ideal para uma vida digna, vez que o mercado hierarquizou a sociedade entre aqueles que podem consumir e aqueles não podem, desumanizando-a, tornando valores patrimoniais mais importantes que valores humanos, ao invés de promover o desenvolvimento financeiro.

Pois o certo é que o humanismo não se tem feito acompanhar senão de uma prática muito aquém dos prometidos mundo e fundos. Tem sido algo muito mais retórico do que real. Bom para a auto-estima das pessoas patrimonializadas e dos países ditos desenvolvidos, mas incapaz de esconder a vexatória verdade de que somente uma micro-minoria de seres é que vive de regular para ótimo. Já a macromaioria, muito ao contrário, vive mesmo é de ruim para péssimo (BRITTO, 2016, p. 44, grifo do autor).

Com isso, surge o direito para declarar a condição de dignidade inata aos seres humanos (BRITTO, 2016), tentando por um limite aos danos sociais gerados pelo mercado e pela ausência de responsabilização social das companhias, evitando que a humanidade seja tratada como insumo na cadeia produtiva.

"Embora assuma concreção como direito individual, a dignidade da pessoa humana, enquanto princípio, constitui, ao lado do direito à vida, o núcleo essencial dos direitos humanos." (GRAU, 2015, p. 193).

Assim, a conscientização dos investidores e dirigentes empresariais deve ter por base o respeito aos Direitos Humanos, internacionalmente reconhecidos como essenciais a todas as pessoas no planeta.

Tomar os Direitos Humanos como referência, principalmente para as transnacionais, torna 
mais homogênea as atividades positivas a serem realizadas pelas companhias, possibilitando ainda a adoção de ações especificas conforme cada povo anseie, reduzindo suas mazelas.

Importante esclarecer ainda, que a nível internacional inexiste qualquer tipo de normatização que estabeleça sanções às companhias pelas violações a Direitos Humanos ocorridas no exercício de sua atividade, deixando-as a cargo de sua própria ética, quando não à legislação interna dos Estados.

No mais, "a ideia de que empresas poderiam ter responsabilidades relativas aos direitos humanos, independentemente de exigências legais em seus países de atuação, é nova e ainda não é aceita universalmente." (RUGGIE, 2014, p. 28).

Vale mencionar, que ainda na década de 1990, a União Europeia publicou a chamada "Resolução sobre as normas da UE para as empresas europeias que operam nos países em desenvolvimento: para um Código de Conduta Europeu” (UNIÃO EUROPEIA, 1999).

Tal instrumento visa, conforme seu nome sugere, estabelecer um código de conduta a ser seguido pelas transnacionais europeias que atuam em países em desenvolvimento, tratando-se de recomendações que almejam contribuir para a redução das desigualdades sociais e maior respeito à dignidade humana.

Com isso, a partir da visão de Amartya Sen (2010), entende-se que é importante dar valor a outros elementos que não apenas àqueles relativos ao mercado, haja vista a vida humana se constituir de relações e liberdades de natureza social, financeira, política e outras mais, capazes de agregar conteúdo à dignidade humana.

Ademais, a sociedade global espera das companhias muito mais do que tem sido feito (SANTONJA, 2009), pois o cunprimento de sua função social nos moldes atuais ainda não foi capaz de impedir o aumento dos males econômicos modernos.

Como é de se imaginar, mudanças ensejam resistência, e com essa não será diferente, principalmente por envolver a redução do lucro ante o dispêndio de capital no custeio de atividades sociais.

“Aqueles que se beneficiam do sistema atual resistirão à mudança, e eles são muito poderosos. Mas as forças a favor da mudança já foram postas em movimento. Haverá reformas, mesmo que sejam graduais e parceladas." (STIGLITZ, 2007, p. 74-75).

É importante destacar que uma sociedade que possui pleno desenvolvimento está mais apta a manter o mercado em funcionamento, tornando-o rentável para as companhias, em virtude do aumento de consumidores.

Mesmo que a globalização não seja algo visível na vida de muitos, a todos ela atingiu, ainda que de forma indireta, pois inevitavelmente seus efeitos são sentidos em diferentes países através do mercado, do meio ambiente ou de outra maneira.

Aponta Stiglitz (2007, p. 86-87) que "a maioria de nós sempre viverá localmente - em nossas comunidades, estados, países. Mas a globalização significa que somos, ao mesmo tempo, 
parte de uma comunidade mundial."

E por todos serem integrantes de uma comunidade mundial, que se têm os Direitos Humanos como o melhor ponto de partida para o estabelecimento de ações sociais positivas por parte das empresas, elevando a qualidade de vida de milhões de pessoas ao redor do planeta.

Nesses termos, a sociedade clama por mudanças quanto à ampliação da responsabilidade corporativa a partir de uma exploração mais humanizada do mercado e que seja capaz de reverter todos os males causados pelo capitalismo predatório e agravados pela globalização.

Só assim, "esta realidad da lugar a un modelo capitalista menos economicista, más humanista y solidario y al mismo tiempo más rentable, que afirma una economía de mercado sana y eficiente en el marco de la globalización, basada en la RSE como nueva y eficaz herramienta de gestión empresarial." (SANTONJA, 2009, p. 28).

Com isso, através da experiência comercial adquirida com a aplicaçao do sistema capitalista nos últimos séculos, conclui-se que a responsabilização social das companhias pode ser considerada uma das melhores ferramentas atuais para prover o desenvolvimento humano na tentativa de combater as disccrepâncias econômicas e sociais entre aqueles afortunados e os que não detêm sequer condições minimas de subsistência.

\section{CONCLUSÃO}

Pôde-se notar que o processo de globalização surgiu sob forte influência do mercado, ante a adoção do capitalismo como principal sistema econômico dos últimos séculos, remodelando-se sempre que necessário.

O liberalismo econômico idealizado por Adam Smith foi responsável por permitir que as relações comerciais se desenvolvessem de maneira predatória, sob a crença de que o desenvolvimento social seria um reflexo do mercado.

Ante os severos danos sociais causados pelo mercado à sociedade, o Estado emerge com políticas públicas voltadas a garantir o bem-estar coletivo, o que demonstrou ser inviável sem a colaboração da iniciativa privada ante a oneração dos dispêndios públicos.

Destarte surge o neoliberalismo almejando reduzir os problemas causados pelo liberalismo através do dirigismo estatal à econômica de mercado, permitindo diferentes povos crer novamente em um real desenvolvimento social.

Tal expectativa foi renovada com o advento da globalização e a intensificação das relações sociais, financeiras e econômicas, no entanto, cada vez mais o desenvolvimento social se mostrou distante de acabar com a pobreza, principalmente em países não desenvolvidos.

A maneira como as companhias têm atuado desde então, pautadas na mobilidade, acabou 
por colocar o Estado moderno em uma posição de subserviência em relação ao capital, o qual tem sido usado como ferramenta de poder, ensejando consideráveis abusos econômicos.

Com isso, valores humanos foram deixados de lado, perdendo espaço para o mero acúmulo de capital, o qual passou a protagonizar as relações de mercado.

Assim, o capital deixou de ser uma ferramenta para a promoção do desenvolvimento e se tornou o fim da atividade econômica, limitando a função social da empresa apenas a gerar lucro, dividindo-o entre seus investidores.

Ante o clamor social por mudanças, tem-se que a abrangência da responsabilidade corporativa deve ir além do mero lucro, valendo-se de uma gestão empresarial mais humanizada a fim de promover o real desenvolvimento social, com base nos Direitos Humanos, impedindo assim, que o capital segregue milhões de pessoas pelo mundo.

Desta maneira, adotar um modelo de responsabilidade social que beneficie efetivamente a coletividade, reduzindo as mazelas trazidas pelo capitalismo e pela globalização, se mostra uma necessidade imediata, sendo ainda um dever moral das companhias, compensando a sociedade pelos danos causados com a exploração dos recursos humanos, naturais e com a centralização de capital ao longo das últimas décadas.

Logo, o cumprimento da função social não deve ser tido como um dispêndio, mas sim como um investimento no bem-estar social e no desenvolvimento humano, pois de nada vale acumular capital se isso custar a dignidade humana.

Deste modo, entende-se que a empresa não deve servir apenas aos investidores, mas também à sociedade, sem tornar o Estado refém de seus interesses.

Para tanto, adotar uma perspectiva macroeconômica na gestão empresarial se mostra essencial, vez que as companhias integram algo muito maior que o mercado mundial, devendo assim considerar em suas condutas uma política mais humanista, para que só então seja possível reverter os males sociais.

\section{REFERÊNCIAS}

BAUMAN, Zygmunt. Capitalismo parasitário e outros temas contemporâneos. Tradução Eliana Aguiar. Rio de Janeiro: Zahar, 2010.

BAUMAN, Zygmunt. Globalização: as consequências humanas. Tradução Marcus Penchel. Rio de Janeiro: Zahar, 1999.

BAUMAN, Zygmunt. O mal-estar da pós-modernidade. Tradução Mauro Gama. Rio de Janeiro: Zahar, 1998.

BRITTO, Carlos Ayres. O humanismo como categoria constitucional. Belo Horizonte: Fórum, 
2016.

GRAU, Eros Roberto. A ordem econômica na Constituição de 1988. 17. ed. São Paulo:

Malheiros, 2015.

RUGGIE, John Gerand. Quando os negócios são apenas negócios: as corporações multinacionais e os direitos humanos. São Paulo: Planeta Sustentável, 2014.

SANTONJA, Aldo Olcese. El capitalismo humanista. Madrid: Marcial Pons, 2009.

SEN, Amartya. Desenvolvimento como liberdade. Tradução Laura Teixeira Motta. São Paulo: Companhia das Letras, 2010.

STIGLITZ, Joseph Eugene. Globalização: como dar certo. Tradução Pedro Maia Soares. São Paulo: Companhia das Letras, 2007.

UNIÃO EUROPEIA. Resolução sobre as normas da UE para as empresas europeias que operam nos países em desenvolvimento: para um Código de Conduta Europeu. Jornal Oficial da União Europeia, Luxemburgo, n. 104, p. 180, 14 abr. 1999.

Como citar: OLIVEIRA, Jeferson Sousa; BENACCHIO, Marcelo. Responsabilidade corporativa como ferramenta de desenvolvimento socioeconômico. Revista do Direito Público, Londrina, v. 13, n. 3, p. 175-188, dez. 2018. DOI: 10.5433/24157-108104-1.2018v13n3 p 175. ISSN: 1980$511 X$.

Recebido em: 28/09/2018

Aprovado em: 07/11/2018 